\title{
Sino-orbital Plasmacytoma: A Rare Entity
}

\author{
${ }^{1}$ Anand Subash, ${ }^{2}$ Ashok K Gupta, ${ }^{3}$ Abhijeet Singh, ${ }^{4}$ Sandeep Bansal
}

\begin{abstract}
Tumors of plasma cell origin are termed as plasmacytomas. They can be primary or secondary. Primary tumors are invasive locally and do not metastatize. Involvement of the eye and orbit is very rare, and only few cases have been reported around the globe. We outline the case of a 48-year-old male, who presented with primary plasmacytoma of the maxilla and orbit, and how it was managed using the combined approach technique.
\end{abstract}

Keywords: Multiple myeloma, Plasmacytoma, Sino-orbital neoplasms.

How to cite this article: Subash A, Gupta AK, Singh A, Bansal S. Sino-orbital Plasmacytoma: A Rare Entity. Clin Rhinol An Int J 2017;10(3):163-165.

\section{Source of support: Nil}

\section{Conflict of interest: None}

\section{INTRODUCTION}

Tumors of plasma cell origin are termed as plasmacytomas. They can be primary or secondary. Primary tumors are invasive locally and do not metastatize, unlike secondary plasmacytomas that are manifestations of multiple myeloma and are invariably metastatic. Involvement of the eye and orbit is very rare and only few cases have been reported around the globe. ${ }^{1}$ We present the case of a 48-year-old male who presented with primary plasmacytoma of the maxilla and orbit.

\section{CASE REPORT}

A 48-year-old male solider presented with progressive decrease in mouth opening and bleeding from the nose for the past 1 year. Patient was initially investigated at other hospitals and was treated symptomatically. A diagnostic nasal endoscopy revealed a friable mass filling the right nasal cavity. At presentation, patient also

\footnotetext{
${ }^{1,3}$ Junior Resident, ${ }^{2}$ Professor and Head, ${ }^{4}$ Associate Professor

${ }^{1-4}$ Department of Otolaryngology Head and Neck Surgery Postgraduate Institute of Medical Education and Research Chandigarh, India

Corresponding Author: Ashok K Gupta, Professor and Head, Department of Otolaryngology Head and Neck Surgery Postgraduate Institute of Medical Education and Research Chandigarh, India, Phone: +911722756766, e-mail: drashokpgi@ hotmail.com
}

had blurring of vision in the right eye and diplopia. A contrast-enhanced computed tomography $(\mathrm{CT})$ revealed heterogeneous soft tissue filling the right nasal cavity, right paranasal sinuses, and extending to the infratemporal fossa and right orbit (Figs 1 and 2). A biopsy from the tumor came out to be plasmacy toma. This diagnostic surprise warranted further workup to confirm if it was a primary or secondary plasmacytoma. A skeletal profile was ordered (Fig. 3); a bone marrow study was performed and was unremarkable. After confirming a diagnosis of primary plasmacytoma, a combined approach of subtotal maxillectomy with endoscopic excision of orbital tumor was decided on. This approach helped better visualization of the disease, allowing complete removal with conservation of orbital contents and thus preserving

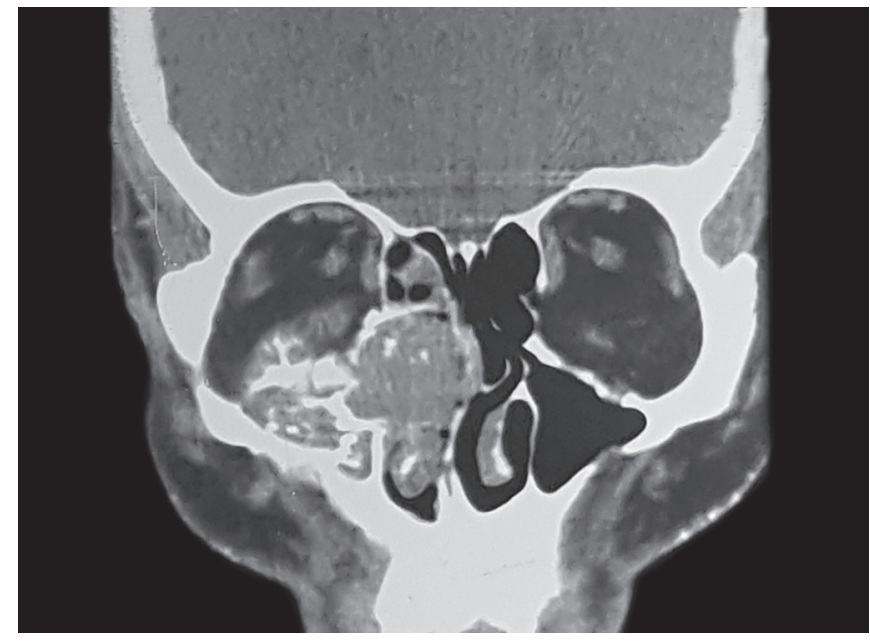

Fig. 1: Contrast-enhanced CT of paranasal sinus (coronal)

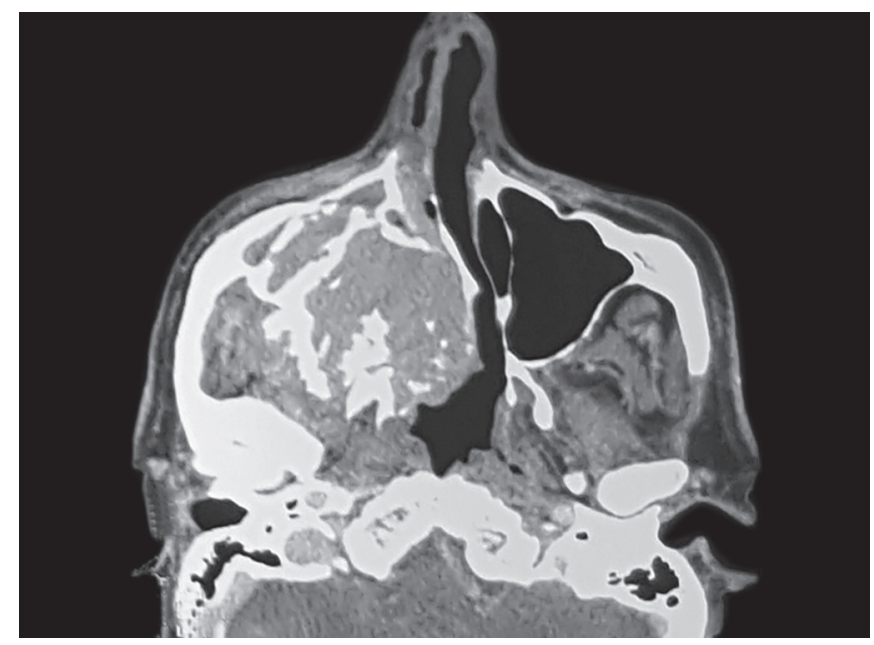

Fig. 2: Contrast-enhanced CT of paranasal sinus (axial) 


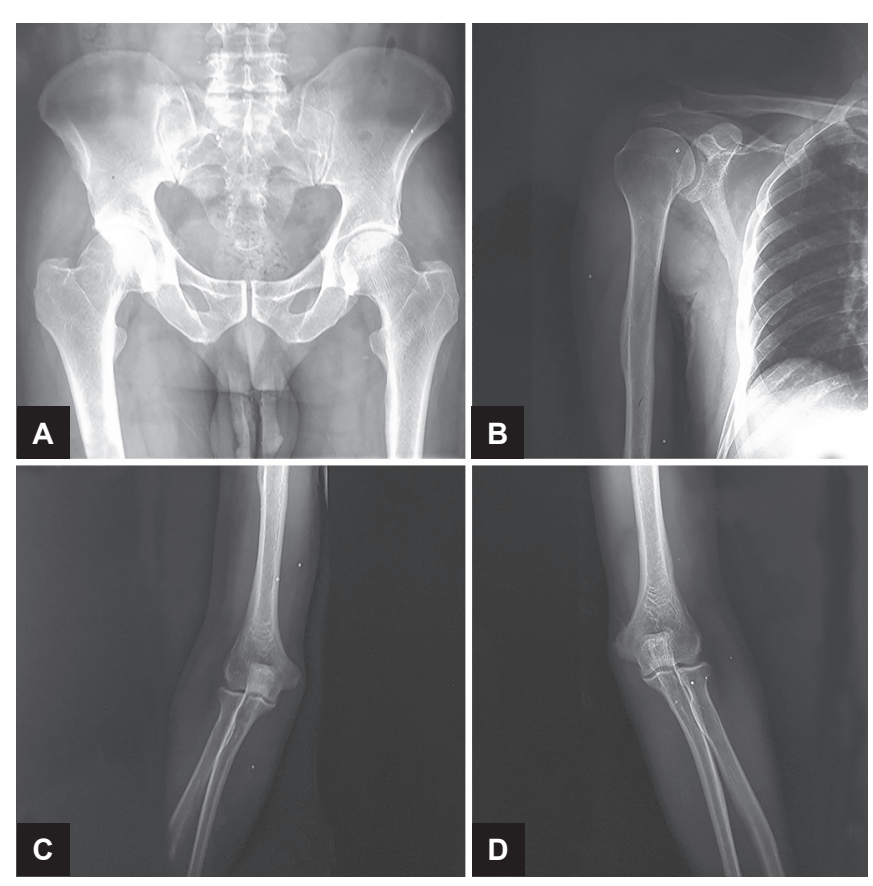

Figs $3 A$ to D: Skeletal profile

the vision and cosmesis. Despite tumor-free resection margins, patient was given 46 gray (Gy) in 23 fractions of radical radiotherapy and four cycles of chemotherapy over 4 weeks. A whole body positron emission tomography (PET) CT was done to rule out distant metastasis (Fig. 4). Patient has been symptom-free and is on regular follow-up with nasal endoscopy for more than 2 years now (Figs 5 and 6).

\section{DISCUSSION}

B-lymphocytes can transform to immunoglobulin producing cells and are termed plasma cells. Tumors of plasma cell origins are termed as plasmacytomas. The criteria for the diagnosis of primary plasmacytoma include a negative nodal status, a skeletal survey, a bone marrow

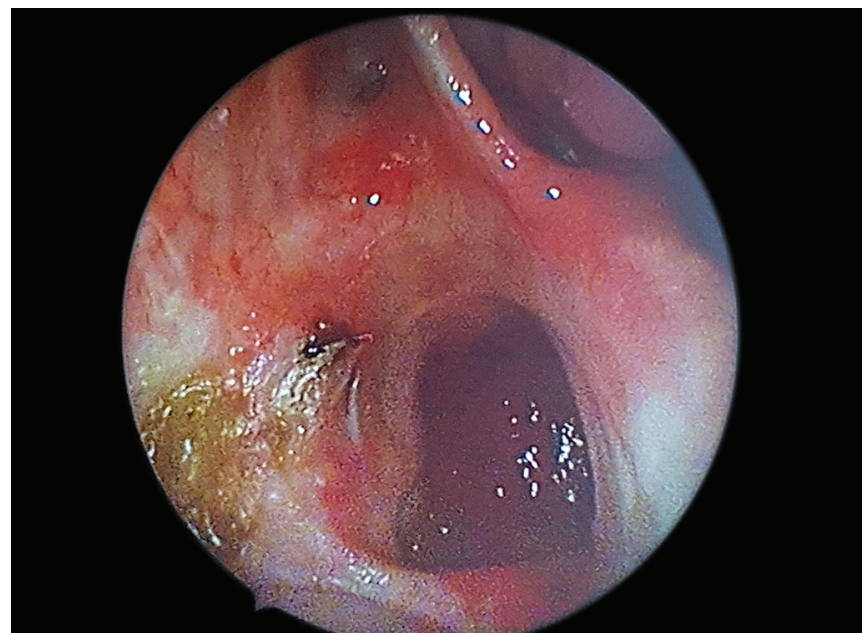

Fig. 5: Postoperative endoscopy: well-healed cavity (2 years)

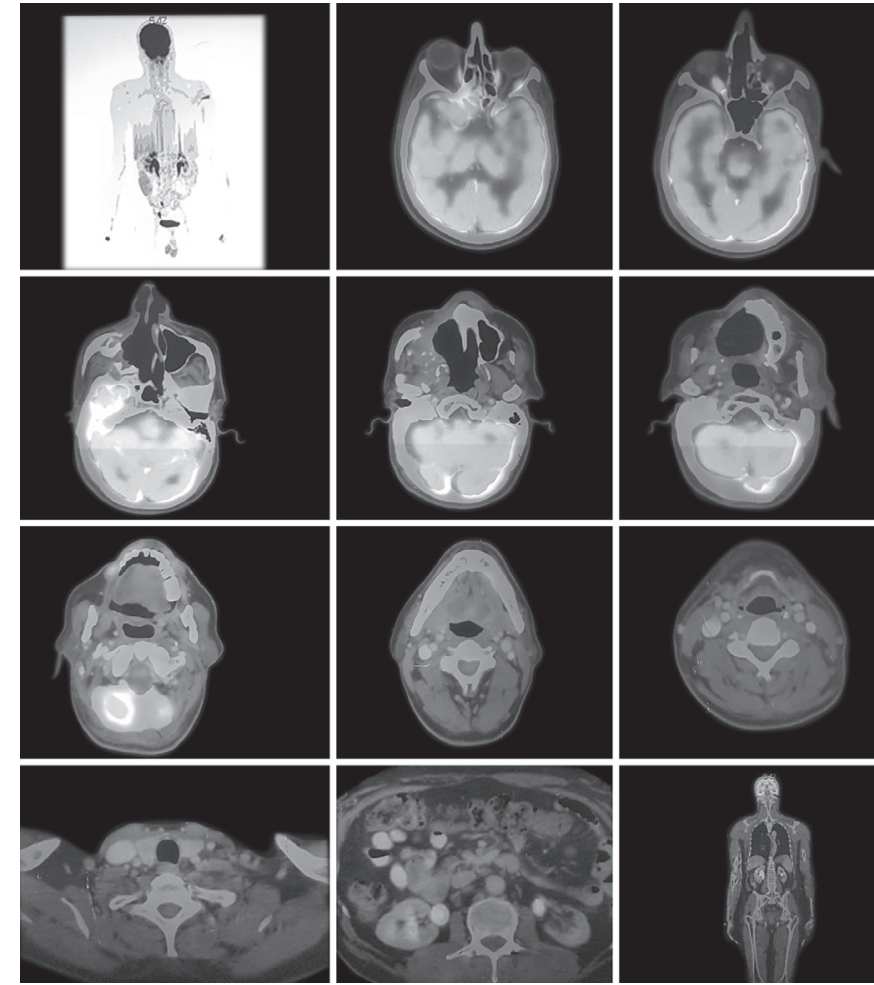

Fig. 4: Whole body PET-CT

study, and appropriated whole body imaging. ${ }^{1}$ Treatment of plasmacytoma includes external beam radiotherapy or local excision..$^{2-4}$ The mean survival is over 8 years. ${ }^{3,5}$

Orbital involvement in multiple myeloma is uncommon. Bonavolontà et al, ${ }^{6}$ who studied orbital tumors extensively, have reported that orbital plasmacytoma has a prevalence of $3 \%$ and accounts for $<1 \%$ of total orbital lesions. In our case, the primary site of origin was maxilla and the tumor had extended to orbit, which is extremely rare.

Using a combined approach, organ preservation can be better performed. In our case, use of endoscopes provided better visualization and helped us in complete extirpation of tumor with preservation of orbital contents

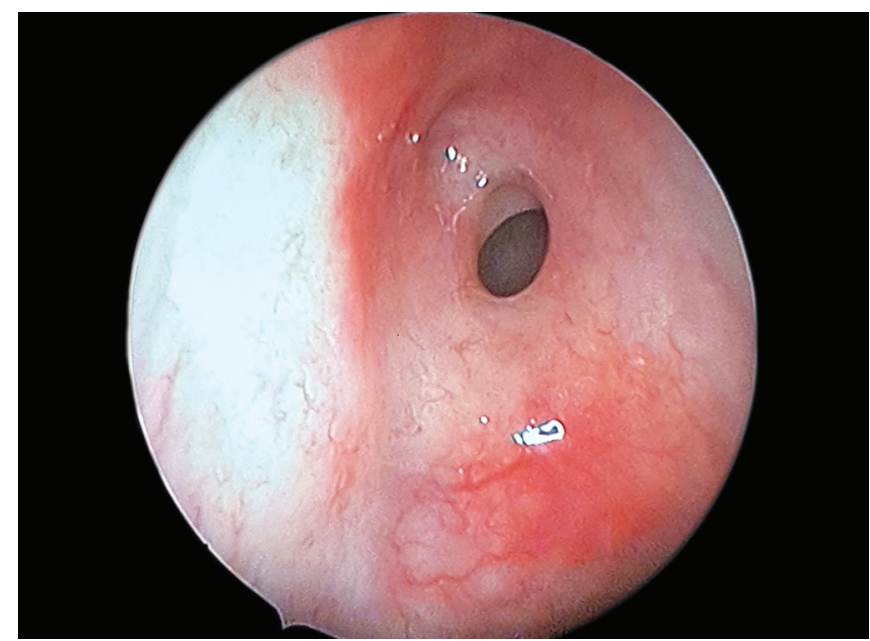

Fig. 6: Postoperative endoscopy: sphenoid ostium (2 years) 


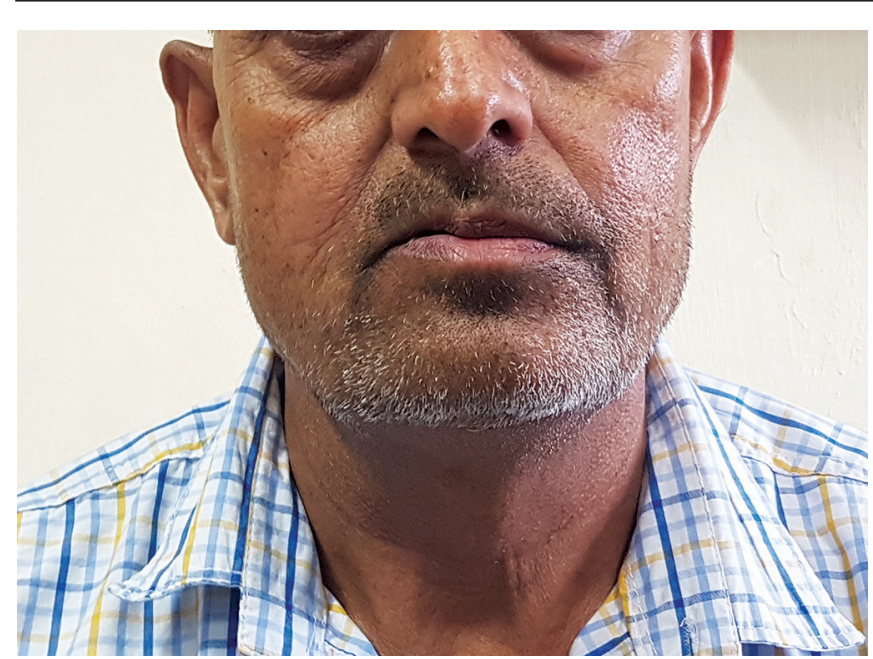

Fig. 7: Patient after 2 years of surgery

and orbital sling. This prevented postoperative diplopia and maintained the esthetics of face (Fig. 7).

\section{CONCLUSION}

Sino-orbital plasmacytoma is a rare tumor. Appropriate treatment includes surgical extirpation followed by concurrent chemoradiotherapy. If treated appropriately, the disease has a good prognosis.

\section{REFERENCES}

1. Adkins JW, Shields JA, Shields CL, Eagle RC Jr, Flanagan JC, Campanella PC. Plasmacytoma of the eye and orbit. Int Ophthalmol 1996-1997;20(6):339-343.

2. Boud N, Sullivan T, Whitehead K. Primary extramedullary plasmacytoma of the orbit. Aust N Z J Ophthalmol 1995 Aug;23(3):235-239.

3. De Smet MD, Rootman J. Orbital manifestations of plasmacytic lymphoproliferations. Ophthalmology 1987 Aug;94(8): 995-1003.

4. Bergsagel DE, Pruzanski W. Syndromes and special presentations associated with multiple myeloma. In:Wiernik $\mathrm{PH}$ Canellos GP, Dutcher JP, Kyle RA, editors. Neoplastic diseases of the blood. 3rd ed. New York: Churchill Livingston; 1996. p. 585-599.

5. Shields JA. Lymphoplasmacytoid tumors. In:Shields JA, editor. Diagnosis and management of orbital tumors. Philadelphia: W.B. Saunders; 1989. p. 330-334.

6. Bonavolontà G, Strianese D, Grassi P, Comune C, Tranfa F, Uccello G, Iuliano A. An analysis of 2,480 space-occupying lesions of the orbit from 1976 to 2011. Ophthal Plast Reconstr Surg 2013 Mar-Apr;29(2):79-86. 